\title{
On the excitation of electricity by pressure and friction
}

\section{H. Fritsch}

To cite this article: $\mathrm{H}$. Fritsch (1878) On the excitation of electricity by pressure and friction, Philosophical Magazine Series 5, 6:37, 316-317, DOI: 10.1080/14786447808639518

To link to this article: http://dx.doi.org/10.1080/14786447808639518

曲 Published online: 13 May 2009.

Submit your article to this journal ๘

Џ Article views: 2

Q View related articles ¿ 
trary case, rays of the same wave-length, taken from different spectra, may have notably different properties.

We can, however, already state that, the intensity being the same in the red for the four spectra, the weakening towards the violet varies with each source, according to a certain function of the temperature; and without being able yet to attempt a measurement of this, we can already arrange them in the order of increasing temperatures:-moderator lamp ; stearine candle; illuminatinggas, of which I have not given the less-accordant Tables ; Drummond light; electric light, and, lastly, the solar light, which corresponds to an emission-temperature much higher.than that of the electric light, in spite of the uncertainty caused by the absorptions it has undergone from its transmission through the gaseous envelopes of the sun and our atmosphere.

It will be possible to make rigorously exact measurement of the temperatures in the spectrometric way as soon as we know the precise law of emission for all the radiations and the numerical constants for each wave-length. The results contained in this Note may be regarded as a first essay towards the solution of this important question.-Comptes Rendus de l'Académie des Sciences, August 19, 1878, tome lxxxvii. pp. 322-325.

\section{ON THE EXCITATION OF ELECTRICITY BY PRESSURE AND FRICTION. BY H. FRITSCH, OF KöNIGSBERG, PRUSSIA.}

1. It is well known that many crystalline bodies can be powerfully electrified by pressure. This, however, takes place in each case only under a perfectly definite condition. Calc-spar becomes electric only when pressed against another substance, never when pressed against another piece of calc-spar. Three pieces of calcspar were laid one upon another; a pressure was then exerted upon the uppermost, which would have made each of the pieces singly distinctly electric: the central piece proved to be quite devoid of excitation; only the two outer ones possessed the usual quantity of electricity. If two calc-spars were pressed against one another, the surfaces which were in contact with the foreign bodies by which the pressure was exerted exhibited electricity distinctly; the two inner surfaces, where calc-spar had been in contact with calcspar, were without excitation. I have not yet succeeded in carrying out the same experiment with other bodies.

2. According to previous observations, a definite substance, on undergoing friction against another, acquires always a certain invariable electrical excitation independent of the collateral circumstances, and accordingly the nature of the electricity excited is constantly the same. To test the correctness of this position the following experiments were instituted, in which the collateral circumstances were varied as much as possible.

a. With a violin-bow I stroked plates of zinc, copper, brass, and 
four different glasses so that they vibrated transversally; they became only negatively electrified. If the same bow was drawn backwards and forwards lengthwise along the same part of the plate without producing a tone, it became only positively electric.

$b$. Copper plates of 4 and 7 centims. diameter were whipped with white silk in various ways. If the stroke was delivered nearly perpendicular to the plate, the latter became strongly positive; if it was more nearly grazing, the plate became just as strongly negative. Whether the plate was fresh cleaned with hydrochloric acid, or by longer exposure to the air had become tarnished, made no difference, nor yet the size of the plate. Further, by lightly rubbing its entire rim (best with a silk or woollen cloth in the form of cone-cover), the plate is always rendered negative; by hard rubbing with the same silk on the same place, always positive. Coarse woollen cloth appeared to excite less powerfully. Zinc gave the same result.

c. With brass the collateral circumstances appeared to have an influence. A square plate intended for the production of Chladn's sound-figures behaved exactly like the copper plate. The shallow brass scale of a table-balance, however, gave both electricities only when struck with silk, and when its surface was well cleaned. Lastly, an old pound-weight could not be excited in different ways with silk; this could only be accomplished with a violin-bow, according as the bow was applied to its thick main part, or to its thin neck.

d. A small scale-pan of fine silver gave both electricities only with silk, with wool it only became negatively electric.

e. A hard-gum plate always became negative when slowly stroked with a tightly folded linen cloth-when stroked quickly, in otherwise like circumstances, positive. The surface of the band produced the same effect as linen; only for the positive excitation the stroking had to be very rapid.

$f$. White silk always makes the principal-cleavage-surface of gypsum positive, but the second, which exhibits a vitreous lustre, negative; while it makes no difference whether the surfaces of this second cleavage are already present on the piece of gypsum, or are artificially produced by roughly scraping a surface of the principal one.

Many other substances give opposite electric excitation on friction, according to the circumstances - for instance, mica struck with silk, hardgum rubbed with copper, hardgum whipped with silk, glass struck with silk ; I have not, however, succeeded in discovering positive rules for this. The few experiments cited above (from $a$ to $f$ ) even show the impossibility of constructing a series of intensities for frictional electricity. If two bodies are rubbed against one another, the electricity excited in each of them may change into the opposite as the pressure, the velocity, or the direction of the rubbing motion, \&c. varies.-Wiedemann's Annalen, 1878, No. 9. 